PRISCILA GUIRÃO LARA

\title{
EFEITO DO VENENO DE Tityus serrulatus EM CAMUNDONGOS \\ SELECIONADOS GENETICAMENTE PARA MÁXIMA OU MÍNIMA \\ RESPOSTA INFLAMATÓRIA
}

Dissertação Apresentada ao Programa de PósGraduação em Imunologia do Instituto de Ciências Biomédicas da Universidade de São Paulo, para Obtenção do Título de Mestre em Ciências.

Área de concentração: Imunologia

Orientador: Dra. Mônica Spadafora Ferreira

Versão original. 


\section{RESUMO}

LARA, P. G. Efeito do veneno de Tityus serrulatus em camundongos selecionados geneticamente para máxima ou mínima resposta inflamatória. 2012. 96 f. Dissertação (Mestrado em Imunologia) - Instituto de Ciências Biomédicas da Universidade de São Paulo, São Paulo, 2012.

O escorpionismo é considerado um problema mundial de saúde pública, sendo a espécie Tityus serrulatus a principal causadora de acidentes graves no Brasil. Os sintomas do envenenamento abrangem desde dor local até reações sistêmicas severas, como disfunção cardíaca e edema pulmonar agudo, sendo este a principal causa de morte. A quantidade de veneno inoculado, idade, condições físicas e fatores genéticos das vítimas relacionam-se com a gravidade dos sintomas apresentados pelos pacientes. Alguns grupos têm utilizado linhagens de camundongos e ratos, tanto isogênicos quanto geneticamente selecionados como modelos experimentais para o estudo da influência de fatores genéticos na resposta frente a venenos animais. Assim, o presente estudo teve como objetivo avaliar as alterações pulmonares induzidas pelo veneno de Tityus serrulatus, em linhagens de camundongos geneticamente selecionados para máxima (AIRmax) ou mínima (AIRmin) resposta inflamatória aguda, a fim de verificar se fatores genéticos relacionados à resposta inflamatória estão envolvidos na resposta ao veneno. Para avaliar a toxicidade do veneno de Tityus serrulatus (VTs) foi determinada a DL $_{50}$ e observou-se que os camundongos AIRmax e AIRmin são igualmente susceptíveis ao veneno e os animais da linhagem BALB/c se mostraram mais resistentes. Após determinação da $\mathrm{DL}_{50}$, os camundongos foram inoculados s.c. com uma dose subletal do VTs e analisados em diferentes períodos. A análise histológica mostrou que o VTs foi capaz de induzir alterações pulmonares como: edema e hemorragia alveolar nas linhagens AIRmax, AIRmin e BALB/c nas duas primeiras horas, sendo mais significativas nos pulmões dos camundongos AIRmax. A quantificação da atividade da mieloperoxidase (MPO) mostrou que o veneno é capaz de induzir a migração de neutrófilos para o pulmão, com acúmulo mais significativo nos camundongos AIRmax em relação as linhagens AIRmin e BALB/c. Não foi possível observar alterações na permeabilidade vascular pulmonar após a inoculação do VTs. $\mathrm{Na}$ análise fenotípica do infiltrado inflamatório pulmonar, foi observado um aumento mais significativo das células $\mathrm{Ly}_{6 \mathrm{G}} / \mathrm{CD} 11 \mathrm{~b}^{+}$e $\mathrm{F} 4 / 80^{+} / \mathrm{CD} 11 \mathrm{~b}^{+}$nos pulmões dos camundongos. Foram detectadas precocemente citocinas pró-inflamatórias (IL-1 $\beta$, IL-6 e TNF- $\alpha$ ) e quimiocinas (KC, MIP-1 $\beta$, MIP-2, MCP-1, RANTES, GM-CSF) nos pulmões dos camundongos AIRmax e AIRmin. Com isso, os resultados demonstraram que o veneno do escorpião T. serrulatus é capaz de causar uma resposta inflamatória pulmonar aguda, mais exacerbada nos camundongos da linhagem AIRmax em relação a AIRmin, sugerindo que a resposta inflamatória causada pelo veneno é modulada por fatores genéticos selecionados nestas linhagens.

Palavras-chave: Inflamação. Camundongos. Células. Citocinas. Veneno de origem animal. Escorpiões. 


\begin{abstract}
LARA, P. G. Effect of Tityus serrulatus venom in mice genetically selected for maximal or minimal inflammatory response. 2012. 96 p. Masters thesis (Immunology) - Instituto de Ciências Biomédicas da Universidade de São Paulo, São Paulo, 2012.
\end{abstract}

The scorpionism is considered a public health problem worldwide, being the species Tityus serrulatus the main cause of accidents in Brazil. Symptoms of envenomation range from local pain to severe systemic reactions such as cardiac dysfunction and pulmonary edema, which is the leading cause of death. The amount of venom inoculated, age, physical conditions and genetic background of the victims are related to the severity of symptoms reported by patients. Several groups have used strains of mice and rats, both inbred and genetically selected as experimental models to study the influence of genetic factors in the response against animal venoms. Thus, this study aimed to evaluate the action of Tityus serrulatus, in the lung inflammation in strains of mice genetically selected for high (AIRmax) or low (AIRmin) acute inflammatory response to observe if genetic factors are involved in the response to the venom. To evaluate the toxicity of Tityus serrulatus venom (TsV) the $\mathrm{LD}_{50}$ was determined and it was observed that AIRmax and AIRmin mice were equally susceptible to the venom while $\mathrm{BALB} / \mathrm{c}$ mice were more resistant. After determining the $\mathrm{LD}_{50}$, mice were inoculated s.c. with a sublethal dose of $\mathrm{TsV}$ and analyzed in different periods. Histological analysis of lung showed that the TsV was able to induce pulmonary changes such as edema, alveolar hemorrhage in AIRmax, AIRmin and BALB/c mice in the first two hours, decreasing 4 and 8 hours after venom inoculation, being the most significant changes in the lungs of mice AIRmax. The measurement of myeloperoxidase activity (MPO) showed that the venom is capable of inducing migration of neutrophils into the lung, with most significant accumulation in AIRmax mice compared to AIRmin and BALB/c strains. It was not possible to observe changes in pulmonary vascular permeability after VTs inoculation. The phenotypic analysis of the lung inflammatory infiltrate showed a larger increase of $\mathrm{Ly}^{6} \mathrm{G}^{+} / \mathrm{CD} 11 \mathrm{~b}^{+}$and $\mathrm{F} 4 / 80^{+} / \mathrm{CD} 1 \mathrm{~b}^{+}$cells in the lungs of both strains of mice. Proinflammatory cytokines (IL-1 $\beta$, IL-6 and TNF- $\alpha$ ) and chemokines (KC, MIP-1 $\beta$, MIP-2, MCP-1, RANTES, GM-CSF) were detected early in the lungs of AIRmax and AIRmin mice. Thus, the results demonstrated that $T$. serrulatus scorpion venom was able to cause an acute pulmonary inflammatory response, further exacerbated in AIRmax mice in relation to AIRmin, suggesting that the inflammatory response caused by this venom is modulated by genetic factors, which were selected in these lines.

Keywords: Inflammation. Mice. Cells. Cytokines. Animal venom. Scorpions. 


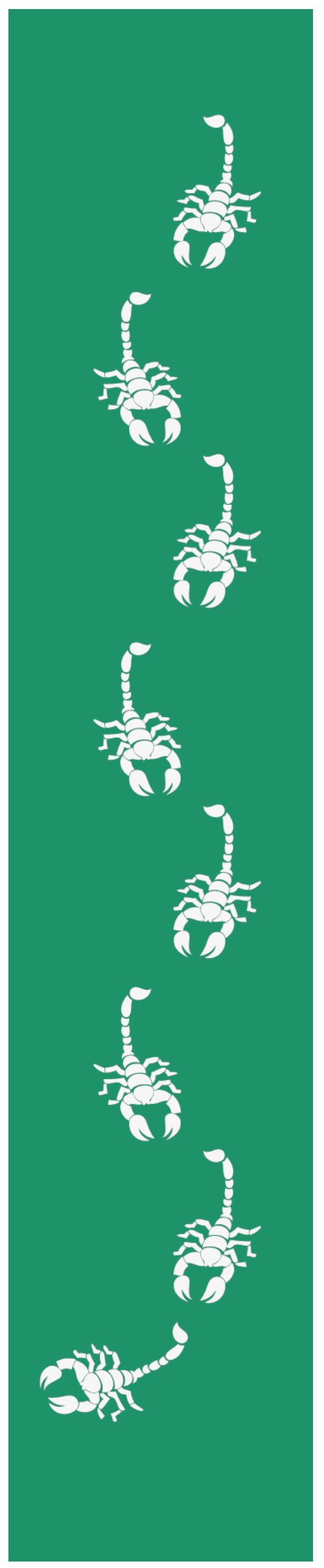

1 INTRODUÇÃO 


\subsection{Epidemiologia e características dos escorpiões}

O escorpionismo representa um problema mundial de saúde pública, sendo que aproximadamente 1,2 milhões de acidentes ocorrem anualmente, com mais de 3.250 óbitos/ano (CHIPPAUX; GOYFFON, 2008). Segundo os autores são escassos os dados epidemiológicos sobre o escorpionismo no mundo e há uma variação geográfica considerável na incidência e severidade dos acidentes. No Brasil, dentre os acidentes causados por animais peçonhentos, o escorpionismo é o que mais vem crescendo ao longo dos anos, segundo dados do Sistema de Informações de Agravos de Notificações, do Ministério da Saúde (Figura 1).

Figura 1 - Notificações de acidentes por animais peçonhentos no Brasil

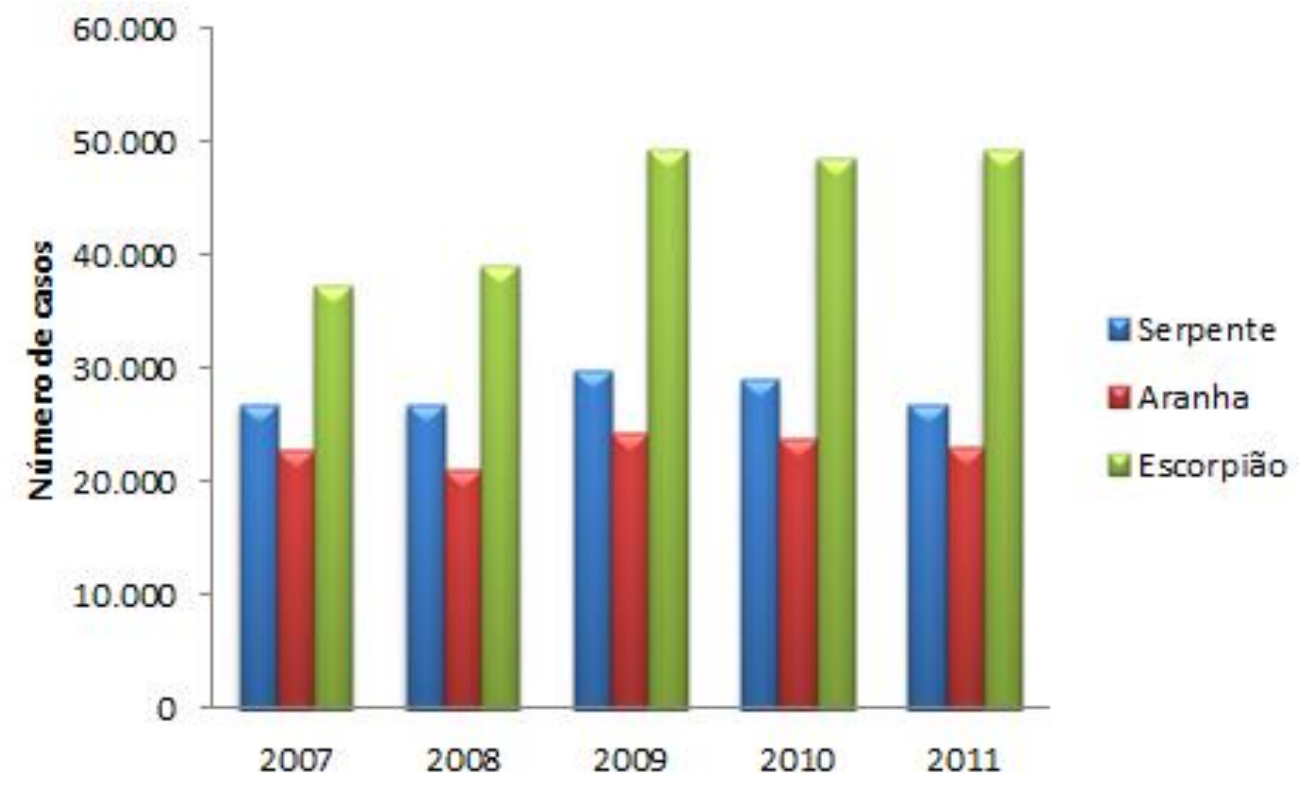

Números de acidentes de 2007 a 2011, classificados pelo tipo de animal.

FONTE: Adaptado de SINAN - Sistema de Informações de Agravos de Notificações (2012)

Os dados epidemiológicos do escorpionismo estão relacionados com a distribuição geográfica das diferentes espécies. Globalmente são conhecidas cerca de 1.500 espécies, com ampla distribuição, tendo representantes da ordem Scorpiones em todos os continentes, com exceção da Antártica (Figura 2) (CHIPPAUX; GOYFFON, 2008; LOURENÇO; CLOUDSLEY-THOMPSON, 1996; SISSOM, 1990). 
Figura 2 - Distribuição mundial dos escorpiões

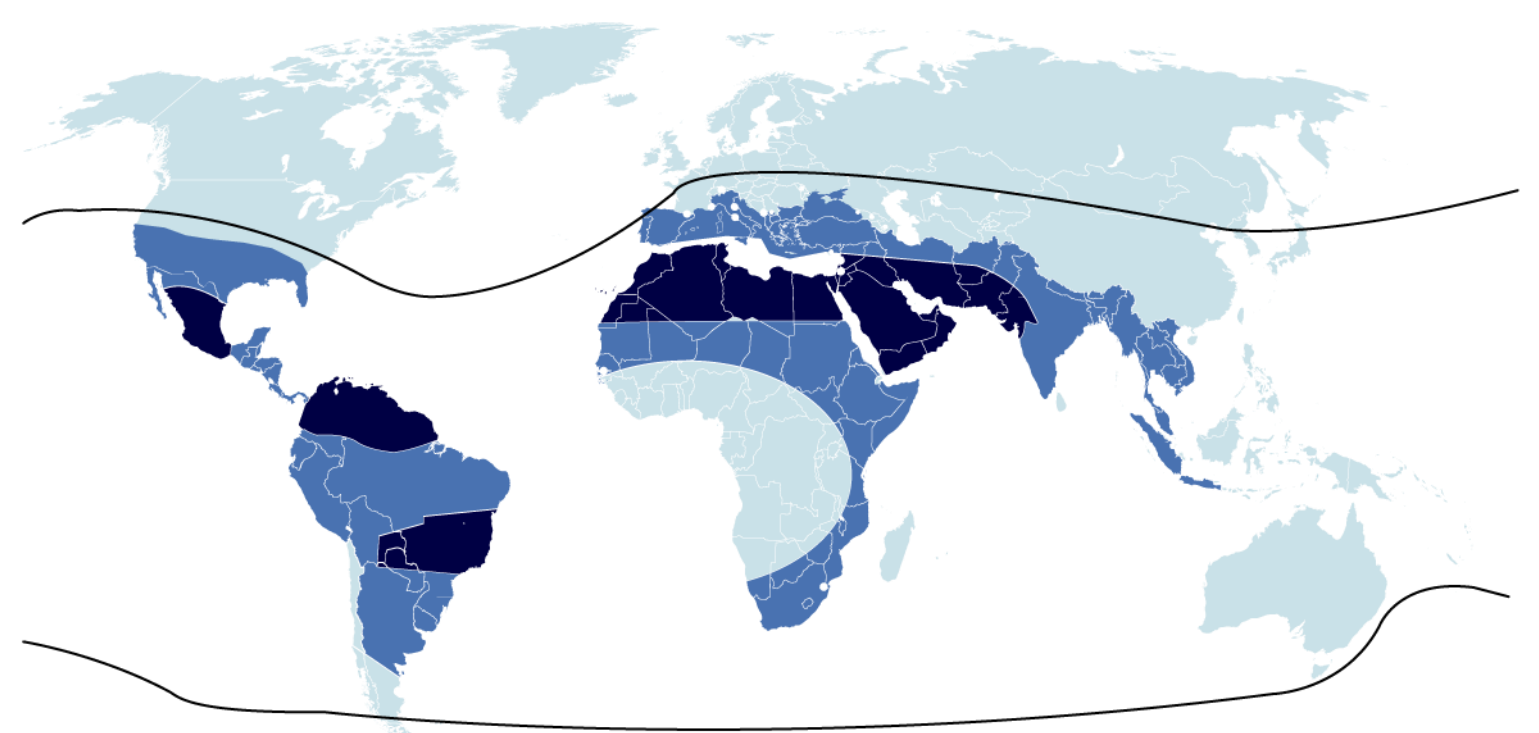

Incidência por 100.000 habitantes
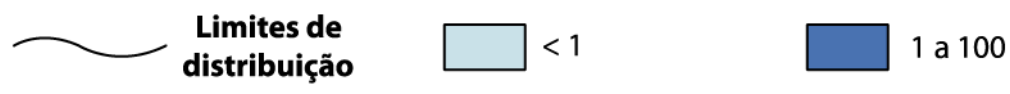

$>100$

FONTE: Modificado de Chippaux e Goyffon (2008).

Os escorpiões são artrópodes quelicerados (subfilo Chelicerata) pertencentes à classe dos aracnídeos (SISSOM, 1990). Eles são facilmente reconhecidos por sua aparência característica, possuem o corpo segmentado em duas partes: o cefalotórax (prossoma), onde se inserem lateralmente quatro pares de patas e na porção anterior é encontrado um par de pedilpalpos, modificados em pinça (utilizados para a detecção e captura de presas) e um par de quelíceras (utilizadas para a manipulação do alimento); o abdome que é dividido em mesossoma e metassoma (cauda), seguido pela vesícula ou télson, onde se localiza a glândula de veneno, terminando no aguilhão, o qual possui em seu ápice dois orifícios por onde o veneno é inoculado (Figura 3) (LOURENÇO; VON EICKSTEDT, 2009). 
Figura 3 - Morfologia geral dos escorpiões

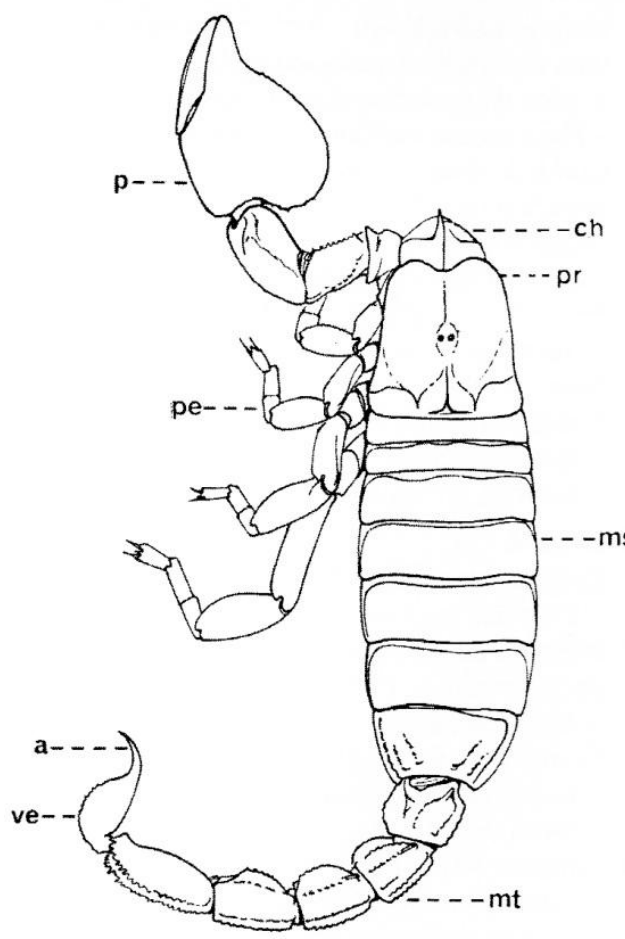

$\mathrm{pr}=$ prossoma, $\mathrm{ch}=$ quelíceras, $\mathrm{p}=$ pedipalpo, $\mathrm{ms}=$ mesossoma, $\mathrm{mt}=$ metassoma, $\mathrm{pe}=$ patas, $\mathrm{ve}=$ vesícula, a = aguilhão.

FONTE: Lourenço e Von Eickstedt (2009).

As principais espécies de escorpiões de importância médica fazem parte da família Buthidae e pertencem a quatro gêneros: Androctonus e Leiurus (África do Norte e Oriente Médio), Centruroides (México e Estados Unidos) e Tityus (América do Sul e Trinidad). São descritas aproximadamente 550 espécies da Família Buthidae, sendo apenas 25 delas capazes de causar acidentes graves ou fatais (LOURENÇO; VON EICKSTEDT, 2009). O gênero Tityus é o maior deles com cerca de 170 espécies conhecidas (BORGES et al., 2010).

No Brasil estão descritas 4 famílias, abrangendo 15 gêneros e 86 espécies de escorpiões, sendo do gênero Tityus os principais escorpiões causadores de envenenamento humano grave (LOURENÇO; VON EICKSTEDT, 2009).

A maioria dos acidentes relaciona-se à espécie Tityus serrulatus (Figura 4) (revisado por COLOGNA et al., 2009), conhecida pela sua coloração amarela característica, podendo atingir cerca de $7 \mathrm{~cm}$ de comprimento. As fêmeas são capazes de se auto-reproduzir por partenogênese, forma de reprodução assexuada, a qual ocorre sem a necessidade da fecundação do gameta masculino. A espécie T. serrulatus possui alta plasticidade ecológica e 
razoável capacidade de distribuição, podendo ser encontrados na maioria dos ambientes terrestres como florestas tropicais, pradarias, savanas, florestas temperadas, cavernas e montanhas (revisado por COLOGNA et al., 2009). Essa espécie é conhecida como oportunista, pois, se adapta muito bem em ambientes modificados pela ação do homem, como em áreas de expansão urbana sem planejamento, com falta de saneamento básico e problemas de coleta de lixo, onde se acumulam baratas e outros insetos, que servem de alimento aos escorpiões (LOURENÇO; VON EICKSTEDT, 2009).

Figura 4 - Escorpião da espécie Tityus serrulatus

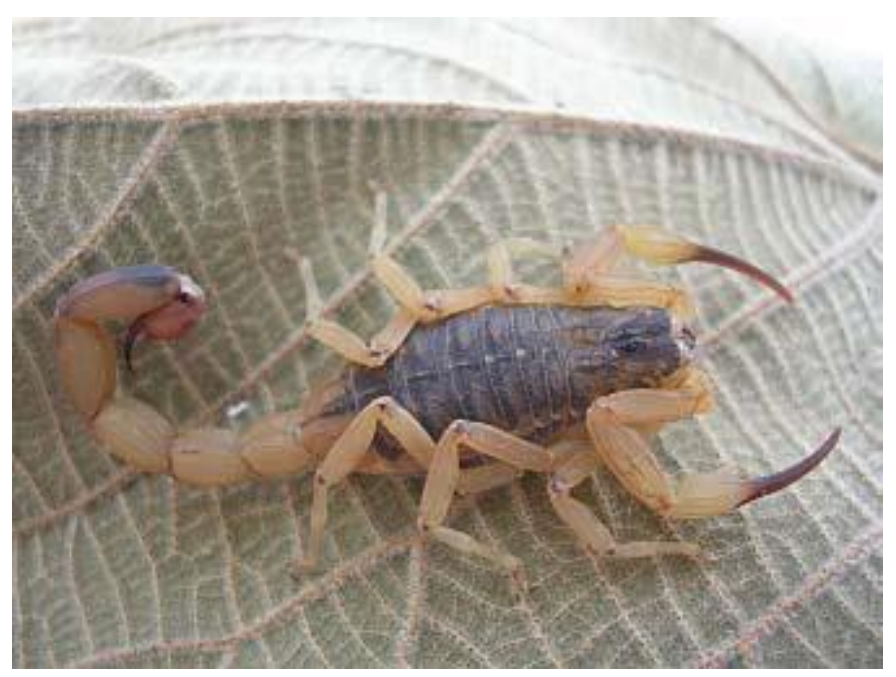

FONTE: Brasil (2009).

No Brasil os escorpiões da espécie Tityus serrulatus podem ser encontrados nos Estados de Minas Gerais, Bahia, Ceará, Pernambuco, Sergipe, Piauí, Rio Grande do Norte, Mato Grosso, Mato Grosso do Sul, Espírito Santo, Rio de Janeiro, São Paulo, Tocantins, Goiás, Distrito Federal e foram introduzidos no Paraná, Santa Catarina e Rio Grande do Sul devido a sua alta plasticidade ecológica (Figura 5). A área de distribuição geográfica dos escorpiões dessa espécie vem crescendo nas últimas décadas, sendo esse um fato preocupante já que os acidentes causados por eles são os que mais levam ao óbito no país (BORGES et al., 2010; BRASIL, 2009; SOUZA et al., 2009). 
Figura 5 - Distribuição geográfica dos escorpiões da espécie Tityus serrulatus no Brasil

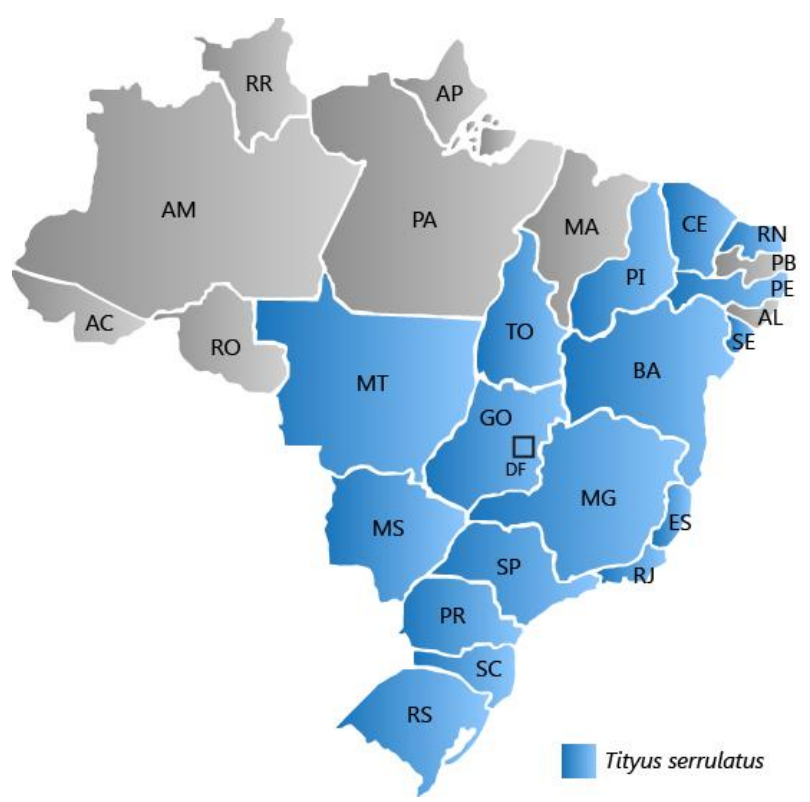

FONTE: Lara (2012).

Os acidentes escorpiônicos são caracterizados por um conjunto de sintomas clínicos, cuja gravidade relaciona-se diretamente à espécie causadora do acidente, à quantidade de veneno inoculado, idade e condições físicas e fisiológicas das vítimas. (CUPO; AZEVEDOMARQUES; HERING, 2009; revisado por PETRICEVICH, 2010).

\subsection{Quadro clínico do escorpionismo e tratamento}

Os envenenamentos por escorpiões abrangem sintomas desde dor local até reações sistêmicas severas levando à morte quando não são devidamente tratadas (CUPO et al., 1994). As picadas atingem predominantemente os membros superiores, acometendo mãos e antebraços.

Os sintomas se iniciam dentro de poucos minutos após a picada e normalmente progridem até a máxima severidade dentro de aproximadamente cinco horas. Durante este período, a massiva liberação de neurotransmissores resulta em sudorese, náuseas e vômitos (MEBS, 2002). Tais sintomas neurológicos são em sua maioria devidos à liberação de catecolaminas das glândulas adrenais ou de acetilcolina dos neurônios parassimpáticos pósganglionares (FREIRE-MAIA; PINTO; FRANCO, 1974). Outros sintomas secundários são observados, sendo os mais comuns: midríase, nistagmo, hipersalivação, disfagia e 
inquietação, nos casos mais graves, os pacientes apresentam sintomas envolvendo o sistema nervoso central, estimulação do sistema nervoso autônomo e ocasionalmente falha respiratória e cardíaca, podendo levar ao óbito. Os acidentes podem ser classificados de acordo com as manifestações clínicas, em leves, moderados e graves: (CUPO et al., 1994; FUNASA, 2001).

a) acidentes leves, nos quais a dor local está freqüentemente presente, podendo ocorrer vômitos, taquicardia e agitação;

b) acidentes moderados onde se observam reações locais e também manifestações sistêmicas como transpiração, náuseas, vômitos, taquicardia, taquipnéia e hipertensão;

c) acidentes graves, caracterizados por manifestações sistêmicas intensas, como hipertensão arterial, taquipnéia e hiperpnéia, taquicardia e bradicardia, sudorese profunda, vômitos profusos, salivação excessiva, alternância entre agitação e exaustão, convulsões, podendo evoluir para choque cardíaco e edema agudo de pulmão, causas mais freqüentes de óbito.

Devido à diversidade das espécies e dos diferentes sintomas por elas apresentados, os dados relativos à classificação clínica dos acidentes escorpiônicos estão sendo revistos por um grupo de especialistas no assunto com o objetivo de criar um consenso mundial (KHATTABI et al., 2011).

O edema pulmonar é a principal causa de morte por envenenamento causado por $T$. serrulatus, especialmente em crianças. São sugeridos dois mecanismos responsáveis pela indução do edema pulmonar sendo eles um de origem cardiogênica, pelo qual ocorre disfunção cardíaca ventricular esquerda e o de origem não-cardiogênica, pela possível liberação de mediadores inflamatórios por meio da ativação da resposta inflamatória e subseqüente aumento da permeabilidade vascular (BENVENUTI; DOWTTS; CARDOSO, 2002; revisado por COLOGNA et al., 2009; FREIRE-MAIA; CAMPOS, 1989; GUERON; ILIA, 1996; MATOS, et al., 1999b; PERES et al., 2009; SEVERINO et al., 2009).

Os casos de envenenamentos humanos dão evidências da origem cardiogênica e não cardiogênica do edema pulmonar, como o relato da ocorrência de edema em seis crianças com idade entre três e nove anos, envenenadas por T. serrulatus, com a ocorrência de dois óbitos (AMARAL; RESENDE; FREIRE-MAIA, 1993). Dos seis pacientes, quatro demonstraram disfunção sistólica ventricular esquerda e dois deles tinham modificações eletrocardiográficas compatíveis com injúria e isquemia miocárdica. Estes achados sugerem que o comprometimento cardíaco possa ter contribuído para a patogênese do edema pulmonar nestes pacientes. No entanto, evidências radiológicas, ecocardiográficas e patológicas indicaram também um aumento da permeabilidade vascular pulmonar como um mecanismo 
patogênico e no exame patológico do pulmão de um dos pacientes, mostrou alterações macro e microscópicas compatíveis com edema pulmonar agudo de origem não cardiogênica.

Em estudo comparativo entre a severidade dos casos de envenenamento causados por escorpiões de diferentes espécies foi observado que os acidentes provocados por escorpiões da espécie $T$. serrulatus foram aproximadamente 26 vezes mais freqüentes do que os acidentes causados pela espécie T. bahiensis (BUCARETCHI et al., 1995). No mesmo estudo foi relatado o caso de uma criança de 2 anos severamente envenenada por $T$. serrulatus, a qual apresentou sintomas clínicos como, vômitos, sudorese profusa, prostração, hipotermia, palidez, hipertonia dos membros superiores, hipertensão arterial, taquicardia e taquipnéia. Após 7 horas da admissão no sistema de saúde o paciente desenvolveu edema agudo pulmonar e queda na função sistólica ventricular esquerda. $\mathrm{O}$ exame de raio-X demonstrou edema pulmonar bilateral sem aumento cardíaco e após 65 horas do acidente o paciente entrou em óbito decorrente da lesão pulmonar aguda associada à falha cardíaca.

Outros casos fatais relatam achados como edema e congestão cerebral, aumento do volume pulmonar com edema alveolar, hemorragia, aumento da consistência e do infiltrado de células polimorfonucleares no pulmão e modificações miocárdicas com edema intersticial e infiltrado inflamatório (CUPO et al., 1994).

Algumas alterações bioquímicas também são observadas, tanto em pacientes quanto em modelos experimentais, como a liberação massiva de angiotensina-II, aumento de marcadores de função hepática, como aspartato aminotransferase, alanina aminotransferase e gamaglutamil transferase. Ocorre também hiperamilasemia, leucocitose, policitemia, hiperglicemia, que é causada pelo aumento da secreção de cortisol e diminuição dos níveis de insulina. Também foi observado em pacientes, alterações nos níveis plasmáticos de cininas (bradicinina e calicreína), sugerindo que tais componentes podem estar envolvidos na patogênese do envenenamento humano (CORRÊA et al., 1997; D'SUZE et al., 2003; FUKUHARA et al., 2004; revisado por PETRICEVICH, 2010; RIBEIRO et al., 2010).

Além dos sintomas clínicos e alterações bioquímicas os pacientes severamente envenenados por escorpiões apresentam um aumento significativo nos níveis plasmáticos de mediadores inflamatórios como IL-1 $\alpha$, IL-1 $\beta$, IL-6, IL-8, IL-10, IFN- $\gamma$, TNF- $\alpha$, RANTES, GM-CSF e NO, pouco tempo após o envenenamento e a presença desses mediadores no soro pode estar diretamente relacionada com as manifestações fisiopatológicas (ABDELHALEEM et al., 2006; D'SUZE et al., 2003; FUKUHARA et al., 2003; SOFER et al., 1996).

Embora ainda existam controvérsias na literatura acerca do uso da soroterapia para o tratamento de acidentes causados por animais peçonhentos, no Brasil existe um consenso 
sobre o efeito benéfico e eficaz desta terapêutica, sendo indicado até mesmo nos casos em que o paciente chega tardiamente ao hospital (CUPO; AZEVEDO-MARQUES; HERING, 2009).

Para o tratamento de acidentes moderados e graves causados por escorpiões é feita a administração endovenosa dos soros anti-escorpiônico ou polivalente anti-aracnídico, sendo iniciado o mais cedo possível para que se torne mais eficaz, já que as toxinas do veneno são rapidamente difundidas do local da picada para os órgãos alvos. Após a utilização do antiveneno, são observadas as condições vitais gerais dos pacientes, principalmente crianças ou aqueles que apresentam quadro severo de envenenamento com manifestações clínicas sistêmicas.

A dor local e os vômitos melhoram pouco tempo após a administração do soro específico devido à rápida neutralização dos antígenos circulantes pelos altos títulos de anticorpos. Em casos onde o paciente apresenta alterações cardiovasculares e pulmonares a soroterapia pode ser insuficiente, sendo necessários cuidados adicionais, como a utilização de eletrocardiograma para acompanhar as alterações cardíacas, e em pacientes com edema pulmonar agudo podendo ser necessária a ventilação artificial mecânica. (revisado por COLOGNA et al., 2009; CUPO et al., 1994; FREIRE-MAIA; CAMPOS, 1989; AMARAL; RESENDE; FREIRE-MAIA, 1993; FUNASA, 2001; REZENDE et al., 1995).

Em casos leves, nos quais ocorre apenas dor local, a infiltração de anestésico é frequentemente utilizada, no entanto, a dor intensa, acompanhada de hipertermia, também é tratada com a administração endovenosa de dipirona (revisado por COLOGNA et al., 2009; FUNASA, 2001; REZENDE et al., 1995).

Apesar da comprovada eficácia da soroterapia, para os acidentes com animais peçonhentos, alguns grupos estudam maneiras de aperfeiçoar e melhorar tal terapia. ChávezOlórtegui et al. (1997) identificaram e descreveram no veneno de T. serrulatus um peptídeo não tóxico, porém, imunogênico chamado TsTNxP (proteína não tóxica de Tityus serrulatos). Anticorpos produzidos contra esse peptídeo foram capazes de neutralizar efetivamente os efeitos letais do veneno, minimizando os problemas éticos na inoculação de proteínas tóxicas e utilização de cavalos. O mesmo grupo mostrou que a imunização com uma combinação de peptídeos desta mesma proteína foi capaz de proteger camundongos desafiados com uma dose letal do veneno (DUARTE et al., 2010). Recentemente, Pucca et al. (2012) desenvolveram anticorpos monoclonais humanizados capazes de neutralizar parcialmente os efeitos bioquímicos e imunológicos causados pelo veneno de $T$. serrulatus, como uma tentativa de diminuir as reações anafiláticas ocorridas pela utilização de soros heterólogos. 
Os sintomas apresentados por pacientes envenenados por escorpiões estão diretamente ligados à composição do veneno (CUPO; AZEVEDO-MARQUES; HERING, 2009).

\subsection{Composição do veneno}

Os venenos de escorpiões consistem de uma mistura de compostos farmacologicamente ativos, principalmente proteínas e peptídeos. Tais proteínas são geralmente de baixo peso molecular e com ponto isoelétrico variando entre 8,0 e 9,0 (MIRANDA; ROCHAT; LISSITZKY, 1964). Outra característica é que a maioria destas toxinas contém de 60-66 resíduos de aminoácidos e quatro pontes dissulfeto (ROCHAT et al., 1976).

Grande parte das toxinas isoladas de venenos de escorpiões atua sobre canais iônicos, como os de sódio $\left(\mathrm{Na}^{+}\right)$, potássio $\left(\mathrm{K}^{+}\right)$, cálcio $\left(\mathrm{Ca}^{2+}\right)$ e cloro $\left(\mathrm{Cl}^{-}\right)$que estão presentes em diferentes tipos celulares como neurônios, células musculares e células do sistema imune, sendo essenciais para a manutenção do equilíbrio eletrolítico do organismo. Tais canais são responsáveis pela geração de sinais elétricos para formação e propagação do potencial de ação, necessários para condução do impulso nervoso, batimentos cardíacos, secreção hormonal, função renal e ativação de células do sistema imune, além de participar das vias de transdução de sinal intracelular dependentes de cálcio (CATTERALL et al., 2007). Assim, os efeitos causados pelo veneno de escorpião, tais como febre, agitação psicomotora, salivação, aumento da mobilidade do trato gastrointestinal, arritmias cardíaca e respiratória, hipertensão arterial seguida de hipotensão, falência cardíaca e edema pulmonar certamente estão relacionados com toxinas que atuam sobre canais iônicos (CUPO, AZEVEDO-MARQUES; HERING, 2009).

As diversas toxinas isoladas de diferentes espécies de escorpiões são classificadas de acordo com a sua ação farmacológica, suas características estruturais da família de peptídeos que as compõem, sua estrutura, mecanismo de ação e os sítios de ligação nos diferentes canais (BECERRIL; MARANGONI; POSSANI, 1997; MOUHAT et al., 2004; POSSANI et al., 2000; POSSANI et al., 1999; TYTGAT; CHANDY; GARCIA, 1999). Assim, as toxinas que possuem cadeia longa e agem sobre canais de sódio foram subdivididas em $\alpha$ e $\beta$ - toxinas. As $\alpha$-toxinas induzem o prolongamento do potencial de ação de nervos e músculos por meio da rápida inativação do canal, já as $\beta$-toxinas induzem uma mudança para potenciais de 
membrana mais negativos através da ativação do canal (JOVER; COURAUD; ROCHAT, 1980; WHEELER; BARHANIN; LAZDUNSKI, 1982).

No Brasil, o veneno do escorpião T. serrulatus, foi fracionado pela primeira vez na década de 1960, resultando em duas frações tóxicas, uma das quais chamada "Titiustoxin ou TsTx" sendo parcialmente caracterizada (GOMEZ; DINIZ, 1966). Estudos subseqüentes realizados por Toledo e Neves, (1976) culminaram na purificação de mais duas toxinas nomeadas como TsTx I e TsTx II. Trabalhos de Possani e colaboradores $(1977,1981)$ deram continuidade aos estudos de fracionamento do veneno de $T$. serrulatus, com o isolamento de cinco proteínas tóxicas e posteriormente a purificação de dez frações, sendo quatro das quais, parcialmente sequenciadas. Atualmente muitas toxinas têm sido isoladas dos venenos de escorpiões com o objetivo de identificar os principais componentes responsáveis pelos efeitos observados no envenenamento (revisado por COLOGNA et al., 2009; GAZARIAN et al., 2005; revisado por PETRICEVICH, 2010).

Dentre as toxinas, que agem em canais de sódio, isoladas do veneno de T. serrulatus, a Ts1 ou TsTX-I, é a principal toxina, correspondendo a cerca de $15 \%$ do veneno solúvel (PESSINI et al., 2001). Sua ação sobre membrana de nervo periférico da rã Xenopus laevis, despolarizou a membrana e induziu atividade espontânea que regride em poucos minutos, com liberação de catecolaminas, aumento da pressão arterial e liberação de dopamina e glutamato (FERNANDES et al., 2004; JONAS et al., 1986; MASSENSINI et al., 1998; VASCONCELOS et al., 2005). Como outros exemplos podem ser citadas as toxinas Ts2, Ts3 e Ts5, sendo esta última, uma $\alpha$-toxina altamente tóxica (revisado por COLOGNA et al., 2009; GONÇALVES et al., 2003).

Outra classe de toxinas são as que atuam sobre canais de potássio $\left(\mathrm{K}^{+}\right)$. Presente nos venenos dos escorpiões brasileiros de interesse médico, $T$. serrulatus, $T$. bahiensis e $T$. stigmurus, a chamada Butantoxina mostrou bloquear canais de potássio de maneira reversível e inibir a proliferação de células T e produção de IL-2 (HOLADAY et al., 2000). Um bom exemplo desta classe de toxinas é Ts7 ou TsTX-K $\alpha$, obtida do veneno de $T$. serrulatus, que age como um potente e seletivo bloqueador de canais de $\mathrm{K}^{+}$dependentes de voltagem em neurônios de mamíferos em cultura (ECCLES et al., 1994). Outras toxinas atuantes em canais de potássio, também isoladas de T. serrulatus, são Ts6, Ts8 e Ts9 (revisado por COLOGNA et al., 2009). As toxinas, isoladas de venenos de escorpiões, com ação sobre estes canais, tem sido sugeridas, para uso em processos de tratamento de câncer, vacinas entre outros (revisado por PETRICEVICH, 2010). 
Além das toxinas que agem em canais iônicos, os venenos de escorpião possuem outras proteínas como enzimas proteolíticas, tais como hialuronidases (POSSANI et al., 1977). Esta enzima responsável pela dispersão do veneno pelos tecidos foi isolada do veneno de T. serrulatus (PESSINI et al., 2001). Um estudo comparativo do veneno de diversos gêneros de escorpião demonstrou a presença de tais enzimas (TAN; PONNUDURAI, 1992). Foram isoladas dos venenos de $T$. serrulatus e $T$. bahiensis enzimas com atividade proteolítica, classificadas como serinoproteinases (ALMEIDA et al., 2002). Foi também isolada do veneno de $T$. serrulatus uma metaloproteinase capaz de clivar seletivamente as proteínas SNAREs (sinaptobrevinas) como a VAMP2 (proteína de membrana associada à vesícula), dentro do tecido pancreático. Essas proteínas SNAREs estão localizadas na membrana celular e são essenciais para o transporte seletivo entre os compartimentos celulares. A ação da metaloproteinase do veneno sobre essas proteínas faz com que elas percam suas funções impedindo, então, que o pâncreas secrete seus produtos e exerça sua função normal. Há, portanto uma relação entre essa metaloproteinase presente no veneno e o desenvolvimento de pancreatite em alguns pacientes envenenados (FLETCHER et al., 2009).

Ferramentas proteômicas têm contribuído muito nos estudos com objetivo de melhor identificar a composição dos venenos de escorpiões, a diversidade das toxinas e até mesmo auxiliando na caracterização de novas famílias de peptídeos, que podem estar intimamente relacionados aos efeitos demonstrados nos envenenamentos (RATES et al., 2008). Um exemplo desses peptídeos são as hipotensinas, presentes no veneno de T. serrulatus que exercem seu efeito anti-hipertensivo de maneira dependente de óxido nítrico (NO) e independente da enzima conversora de angiotensina (ACE) (VERANO-BRAGA et al., 2008).

\subsection{Veneno e toxinas de escorpião e a resposta inflamatória}

Os mecanismos pelos quais as toxinas que compõem os venenos de escorpião são capazes de ativar o sistema imunológico ainda não estão claros, embora diversos grupos sugiram duas possíveis hipóteses: a) Devido à despolarização das células nervosas pelo veneno, ocorre à liberação de neuropeptídios, como a substância $\mathrm{P}$, que se ligam ao seu receptor NK1 (receptor de taquicininas) presente na superfície de células inflamatórias, como macrófagos e mastócitos levando-os à produção e liberação de mediadores inflamatórios; b) As neurotoxinas exercem ação direta nos canais iônicos presentes na superfície das células imunes, e tais canais podem ter um papel importante na ativação de macrófagos e linfócitos, participando da liberação de citocinas, da proliferação, da eliminação de células alvo, da 
adesão celular, da quimiotaxia e da ativação de fatores de transcrição inflamatórios (DEMATOS et al., 2001; FIALHO et al., 2011; MATOS et al., 1999b; PERES et al., 2009). Alguns estudos dão suporte à hipótese da ação dos neuropeptídios (substância P) sobre os receptores NK1, onde se observou uma diminuição da permeabilidade vascular e da injúria pulmonar e maior sobrevida dos animais pré-tratados com o antagonista do receptor NK1. Dessa forma demonstrou-se que a ligação entre o envenenamento e as alterações pulmonares seja consequência da habilidade das toxinas, que compõem o veneno, de induzir a liberação de neuropeptídios (MATOS et al., 1999a, b).

O veneno de $T$. serrulatus é capaz de induzir uma resposta inflamatória sistêmica ocasionando a liberação de mediadores inflamatórios tanto em pacientes (ABDEL-HALEEM, 2006; D'SUZE et al., 2003; FUKUHARA et al., 2003; MAGALHÃES et al., 1999), quanto em modelos experimentais (DE MATOS et al., 1997; PESSINI et al., 2003; PETRICEVICH; PENÃ, 2002).

As alterações pulmonares causadas após o envenenamento são as principais causas de óbito entre os pacientes, sendo assim alvo de estudo. Essas alterações podem ser caracterizadas por infiltrado de células mono e polimorfonucleares (CORRÊA et al., 1997; PERES et al., 2009). O acúmulo de neutrófilos no pulmão após a administração do veneno em camundongos é consequência da liberação de quimiocinas como a $\mathrm{KC}$, citocina indutora de quimio-atração de neutrófilos, sendo sua produção dependente de PAF (do inglês Platelet Activating-factor), fator ativador de plaquetas. Além disso, o veneno é capaz de causar neutrofilia no sangue e consequente diminuição dessa população celular na medula óssea, também de maneira dependente de PAF (BORGES et al., 2000; COELHO et al., 2007). A migração de leucócitos para a periferia e para o tecido também é mediada pela interação entre as moléculas de adesão expressas nos leucócitos e nas células endoteliais, e a expressão de tais moléculas é regulada por citocinas pró-inflamatórias e quimiocinas (LUSTER, 1998). Observou-se que PAF e NO podem ser produzidos localmente e que ambos estão envolvidos na indução do edema de pata com infiltrado de neutrófilos após administração do veneno (SEVERINO et al., 2009).

Outro estudo demonstrou que mastócitos também desenvolvem um papel importante na formação do edema pulmonar induzido pelo veneno de T. serrulatus (DE-MATOS et al., 2001). De maneira contrária, Zuliani et al. (2011) demonstraram que o veneno é capaz de causar um forte edema pulmonar de maneira independente da ativação de mastócitos e que essas células não são ativadas diretamente pelo veneno. 
Alguns estudos também têm mostrado a presença de enzimas proteolíticas capazes de ativar o sistema complemento, importante no contexto do processo inflamatório, podendo diretamente contribuir para a fisiopatologia do envenenamento (BERTAZZI et al., 2003). Existem evidências de que o Sistema Complemento também pode estar relacionado com o processo inflamatório sistêmico provocado pelo veneno em camundongos, através do aumento da atividade lítica do soro após incubação com o veneno, alterações na mobilidade eletroforética do componente C3 e do fator B e pela indução de quimio-atração de neutrófilos (BERTAZZI et al., 2003, 2005).

Estudos realizados in vitro, com macrófagos peritoneais de camundongos estimulados com o VTs e alguns de seus constituintes, sugerem um possível efeito imunomodulador do veneno, demonstrando ser capaz de ativar macrófagos para que liberem citocinas próinflamatórias como IL-1 $\alpha$, IL-1 $\beta$, IL-6 e TNF- $\alpha$, ou anti-inflamatória como IL-10, e também reativos intermediários do oxigênio como $\mathrm{NO}$ e $\mathrm{H}_{2} \mathrm{O}_{2}$ (PETRICEVICH et al., 2007, 2008). Zoccal et al., (2011) também observaram que o veneno total de $T$. serrulatus e algumas frações (Ts1, Ts2 e Ts6) são capazes de ativar in vitro macrófagos murinos, estimulando a produção de óxido nítrico (NO), IL-6 e TNF- $\alpha$. Porém, quando as células eram estimuladas com LPS, a fração Ts2 foi capaz de inibir a produção de tais mediadores e induzir a produção de IL-10, demonstrando mais uma vez, o possível efeito imunomodulador do veneno de $T$. serrulatus. Outro estudo in vitro mostrou que os venenos de escorpiões do gênero Tityus são capazes de ativar neutrófilos humanos, levando à liberação de espécies reativas do oxigênio (ROS) (BORGES et al., 2011).

Recentemente, foi demonstrado que o veneno de $T$. serrulatus é capaz de induzir o recrutamento de células no sistema imune para órgãos linfoides como, baço e linfonodo e para outros locais como peritônio e sangue. O veneno também aumentou os níveis de citocinas séricas como, TNF- $\alpha$ e IL-6 pouco tempo após a administração e de IL-10 mais tardiamente, indicando que o veneno é capaz de induzir uma resposta inflamatória aguda imediata (FIALHO et al., 2011).

\subsection{Influência genética na resposta inflamatória frente a venenos animais}

As variações na severidade e nas manifestações clínicas apresentadas pelos pacientes em resposta a venenos animais relacionam-se tanto com as diferentes características do animal, produtor do veneno, quanto dos pacientes envenenados. Com relação aos animais as características podem ser: gênero, localização geográfica, sexo, hábitos alimentares e variação 
individual podendo influenciar na toxicidade do veneno. Já as características relacionadas aos pacientes incluem: idade, sexo, fatores genéticos, condições fisiológicas e imunológicas. Porém, pouco se sabe sobre a influência desses aspectos nas manifestações clínicas e na severidade dos envenenamentos (PADILLA et al., 2003).

Diversos grupos utilizaram linhagens de camundongos e ratos, tanto isogênicos quanto geneticamente selecionados como modelos experimentais para os estudos de venenos de serpente (CARNEIRO et al., 2008; LIMA et al., 1991), aranhas (TAMBOURGI et al., 1998) e escorpiões (PADILLA et al., 2003; PETRICEVICH; PEÑA, 2002; KRIFI et al., 1998), na tentativa de investigar e esclarecer a susceptibilidade a esses venenos animais.

Petricevich e Peña em 2002 investigaram a susceptibilidade de diversas linhagens de camundongos isogênicos (A/J, BALB/c, C57BL/6 e DBA) ao veneno de T. serrulatus e observaram que há diferenças na dose letal $\left(\mathrm{DL}_{50}\right)$ e sintomas apresentados após administração do veneno.

Para avaliar o impacto do controle genético da imunidade não específica na susceptibilidade a doenças autoimunes, como artrite (VIGAR et al., 2000), tumorigênese (DE FRANCO et al., 2010; RIBEIRO et al., 2005), doenças infecciosas (ARAÚJO et al., 1998; BORREGO et al., 2006) e venenos animais (CARNEIRO et al., 2002, 2008; RAMOS et al., 2004) vem sendo utilizadas linhagens de camundongos geneticamente selecionadas para máxima (AIRmax) ou mínima (AIRmin) resposta inflamatória aguda.

As linhagens AIRmax e AIRmin foram desenvolvidas a partir da seleção genética bidirecional partindo de uma população geneticamente heterogênea $\left(\mathrm{F}_{0}\right)$ derivada do intercruzamento de oito linhagens isogênicas (A/J, DBA/2J, P/J, SWR/J, CBA/J, SJL/J, BALB/cJ e C57Bl/6J). O fenótipo escolhido para a seleção foi baseado na resposta inflamatória aguda (AIR, do inglês acute inflammatory response) por meio da análise do número de leucócitos infiltrantes e da concentração protéica no exudato após 24 horas da injeção subcutânea de partículas de poliacrilamida (Biogel), uma substância não-imunogênica, não biodegradável e quimicamente inerte (BIOZZI, 1998; IBAÑEZ, 1992). Ao longo das sucessivas gerações, evitando consanguinidade, foi alcançada uma diferença de 20 vezes no número de células infiltrantes e de 2,5 vezes de proteínas no exudato. Estas diferenças são o resultado do acúmulo de alelos que possuem efeitos aditivos e opostos na resposta inflamatória aguda. Os camundongos AIRmax e AIRmin mantiveram o fundo genético heterogêneo porém com homozigose nos alelos responsáveis pela resposta inflamatória aguda (CARNEIRO et al., 2009; IBAÑEZ et al., 1992; STIFFEL et al., 1990; VORRARO et al., 2011). 
Os camundongos AIRmin apesar de apresentarem baixa resposta inflamatória comparável à dos camundongos BALB/c, são considerados saudáveis e imunocompetentes. A alta resposta inflamatória apresentada pelos camundongos AIRmax é consequência, entre outros fatores, da produção elevada de neutrófilos pela medula óssea devido a alta responsividade às citocinas granulopoéticas, da produção de altos níveis de fatores quimiotáticos no exudato e da maior resistência a apoptose espontânea apresentada pelos neutrófilos presentes no exsudato inflamatório (RIBEIRO et al., 2003). Além disso, em relação aos camundongos AIRmin mostrou-se ser mais resistente à carcinogênese de pele induzida por DMBA (9,10-dimethil-1,2-benzanthraceno) / TPA (12-O-tetradecanoil-phorbol13acetato) (BIOZZI et al., 1998) e de pulmão induzida por uretana (MARIA et al., 2003), sendo também mais resistentes à infecção causada pelas bactérias Salmonella typhimurium e Listeria monocytogenes (ARAÚJO et al., 1998). Entretanto os camundongos AIRmax apresentam susceptibilidade em relação a outros fenótipos como a artrite induzida por Pristane (VIGAR et al., 2000) e carcinogênese de cólon induzido por DHM (1,2 - dimetilhidrazina) (DI PACE et al., 2006).

Nos estudos com venenos animais utilizando essas linhagens selecionadas para a resposta inflamatória aguda, foram observado que os camundongos AIRmax são mais susceptíveis aos efeitos inflamatórios locais induzidos pelo veneno da serpente Bothrops jararaca (CARNEIRO et al., 2002, 2008) e da lagarta Lonomia obliqua (RAMOS et al., 2004).

Dessa forma o modelo é adequado para o estudo da influência de fatores genéticos na resistência e susceptibilidade a venenos de outras espécies animais, como o escorpião. 


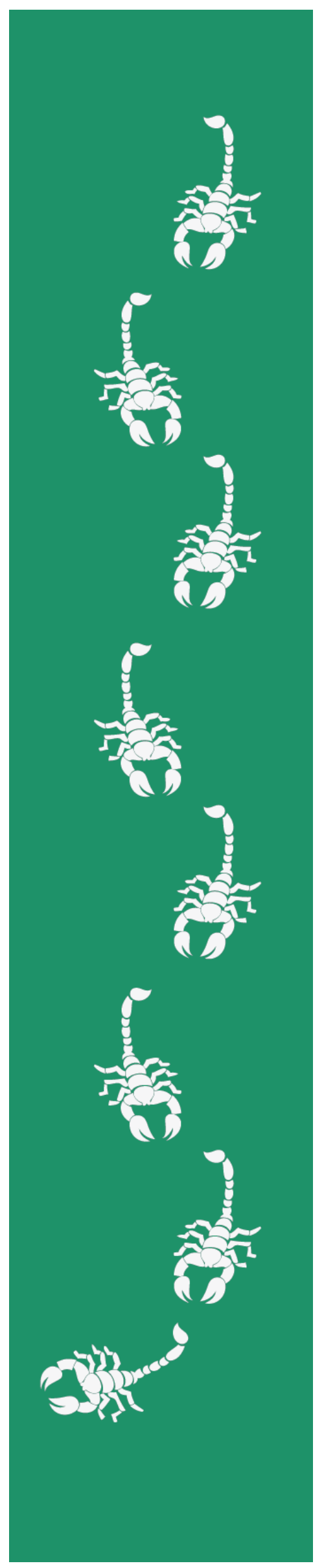

6 DISCUSSÃO 
O veneno de Tityus serrulatus foi capaz de causar alterações pulmonares, tais como edema e hemorragia alveolar, além de induzir a migração de células inflamatórias para a região perivascular pulmonar, nos camundongos AIRmax, AIRmin e BALB/c, sendo mais intensas na linhagem AIRmax.

O infiltrado inflamatório encontrado nos pulmões é caracterizado principalmente por neutrófilos, mas também macrófagos. Foi observado um maior número dessas células na linhagem AIRmax do que em AIRmin.

Citocinas pró-inflamatórias (IL-6, TNF- $\alpha$ e IL-1 $\beta$ ) e quimiocinas (KC, MIP-1 $\beta$, MIP2, MCP-1, RANTES e GM-CSF) responsáveis pela migração de leucócitos foram detectadas precocemente nos pulmões dos camundongos após inoculação do veneno, contribuindo para as alterações pulmonares causadas pelo veneno.

Podemos concluir que a resposta inflamatória pulmonar induzida pelo veneno de Tityus serrulatus é modulada por fatores genéticos selecionados nas linhagens AIRmax e AIRmin. 


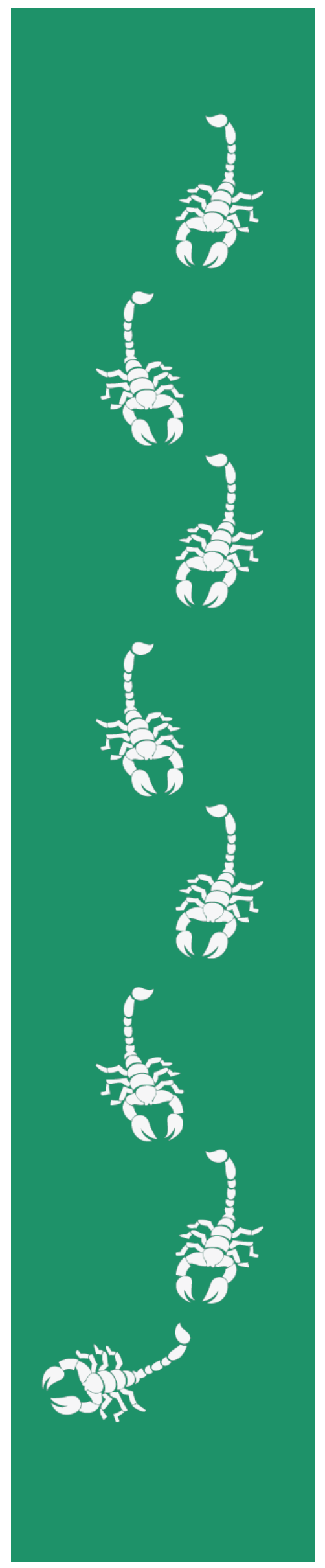

REFERÊNCIAS 
ARNHOLD, J.; FLEMMING, J. Humam myeloperoxidase in innate and acquired immunity. Arch. Biochem. Biophys., v. 500, p. 92-106, 2010.

ABBAS, A.; LICHTMANN, A.; PILLAI, S. Imunologia celular e molecular. 6. ed. São Paulo: Elsevier, 2008.

ABDEL-HALEEM, A. H.; MEKI, A. R.; NAOMAN, H. A.; MOHAMED, Z. T. Serum levels of IL-6 and its soluble receptor, TNF- $\alpha$ and chemokine RANTES in scorpion envenomed children: Their relation to scorpion envenomation outcome. Toxicon, v. 47, p. 437-444, 2006.

ALMEIDA, F. M.; PIMENTA, A. M.; DE FIGUEIREDO, S. G.; SANTORO, M. M.; MARTIN-EAUCLAIRE, M. F.; DINIZ, C. R.; DE LIMA, M. E. Enzymes with gelatinolytic activity can be found in Tityus bahiensis and Tityus serrulatus venoms. Toxicon, v. 40, p. 1041-1045, 2002.

AMARAL, C. F. S.; RESENDE, N. A.; FREIRE-MAIA, L. Acute pulmonary oedema after Tityus serrulatus scorpion sting in children. Am. J. Cardiol., v. 71, p. 242-245, 1993.

ARAÚJO, L. M. M; RIBEIRO, O. G.; SIQUEIRA, M.; DE FRANCO, M.; STAROBINAS, N.; MASSA, S.; CABRERA, W. H; MOUNTON, D.; SEMAN, M.; IBAÑEZ, O. M. Innate resistance to infection by intracelular bacterial pathogens differs in mice selected for maximal or minimal acute inflammatory response. Eur. J. Immunol., v. 28, p. 2913-2920, 1998.

BAUMANN, H.; GAULDIE, J. The acute phase response. Immunol. Today, v.15, p.74-80, 1994.

BD BIOSCIENCES. BD FACSDiva ${ }^{\text {TM }}$ 6.1.3 Software. San Diego, U.S.A.: BD Biosciences. 2009.

BD BIOSCIENCES. BD Cell Quest Pro ${ }^{\text {TM }}$ 0.4.bfb Software. San Diego, U.S.A.: BD Biosciences.

BECERRIL, B.; MARANGONI, S.; POSSANI, L. D. Toxins and genes isolated from scorpions of the genus Tityus. Toxicon, v. 35, p. 821-835, 1997.

BENVENUTI, L. A.; DOWTTS, K. V.; CARDOSO, J. L. Myocardial necrosis after envenomation by the scorpion T. serrulatus. Trans. R. Soc. Trop. Med. Hyg., v. 96, p. $275-$ 276, 2002.

BERTAZZI, D. T.; ASSIS-PANDOCHI, A. I.; AZZOLINI, A. E.; TALHAFERRO, V. L.; LAZZARINI, M.; ARANTES, E. C. Effect of Tityus serrulatus scorpion venom and its major toxin, TsTX-I, on the complement system in vivo. Toxicon, v. 41, p. 501-508, 2003.

BERTAZZI, D. T.; ASSIS-PANDOCHI, A. I.; TALHAFERRO, V. L.; AZZOLINI, A. E.; CROTT, S. P.; ARANTES, E. C. Activation of the complement system and leukocyte recruitment by Tityus serrulatus scorpion venom. Int. Immunopharmacol., v. 5, p. 10771084, 2005.

*De acordo com: ASSOCIAÇÃO BRASILEIRA DE NORMAS TÉCNICAS. NBR 6023: informação e documentação: referências: elaboração. Rio de Janeiro, 2002. 
BHANDARI, V.; ELIAS, J. A. Cytokines in tolerance to hyperoxia-induced injury in the developing and adult lung. Free Radic. Biol. Med., v. 41, p. 4-18, 2006.

BIOZZI, G.; RIBEIRO, O. G.; SARAN, A.; ARAUJO, M. L.; MARIA, D. A.; DE FRANCO, M.; CABRERA, W. K.; SANT'ANNA, O. A.; MASSA, S.; COVELlI, V.; MOUTON, D.; NEVEU, T.; SIQUEIRA, M.; IBAÑEZ, O. M. Effect of genetic modification of acute inflammatory responsiveness on tumorigenesis in the mouse. Carcinogenesis, v. 19, p. 33746, 1998.

BIO RAD, Bio-Plex Manager ${ }^{\mathrm{TM}}$ 6.1 Software. Hercules, U.S.A.: Bio Rad.

BLACKWILL, R. F.; BURKE, F. The cytokine network. Immunol. Today, v. 10, p. 299304, 1989.

BORGES, A.; BERMINGHAM, E.; HERRERA, N.; ALFONZO, M. J.; SANJUR, O. I. Molecular systematics of the neotropical scorpion genus Tityus (Buthidae): The historical biogeography and venom antigenic diversity of toxic Venezuelan species. Toxicon, v. 55, p. 436-454, 2010.

BORGES, A.; HUUB J. M.; OP DEN CAMP, H. J.; DE SANCTIS, J. B. Specific activation of human neutrophils by scorpion venom: A flow cytometry assessment. Toxicol. In Vitro, v. 25, p. 358-367, 2011.

BORGES, C. M.; SILVEIRA, M. R.; APARECIDA, M.; BEKER, C. L.; FREIRE-MAIA, L.; TEIXEIRA, M. Scorpion venom-induced neutrophilia is inhibited by a PAF receptor antagonist in the rat. J. Leukoc. Biol., v. 67, p. 515-519, 2000.

BORREGO A.; PETERS L. C.; JENSEN, J. R.; RIBEIRO, O. G.; KOURY, W. H. C.; STAROBINAS, N.; SEMAN, M.; IBAÑEZ, O. M.; DE FRANCO, M. Genetic determinants of acute inflammation regulate Salmonella infection and modulate Slc11a1 gene (formerly Nramp1) effects in selected mouse lines. Microbes Infec., v. 8, p. 2766-2771, 2006.

BRADLEY, P. P.; PRIEBAT, D. A.; CHRISTENSEN, R. D.; ROTHSTEIN, G. Measurement of cutaneous inflammation: estimation of neutrophil content with an enzyme marker. $\mathbf{J}$. Invest Dermatol., v. 78, p. 206-209, 1982.

BRAIN, S. D. Immunopharmacology of the microcirculation. San Diego: Academic Press, 1994.

BRASIL. Ministério da Saúde. Manual de controle de escorpiões. Brasília: Secretaria de Vigilância da Saúde. Departamento de Vigilância Epidemiológica, 2009.

BUCARETCHI, F.; BARACAT, E. C.; NOGUEIRA, R. J.; CHAVES, A.; ZAMBRONE, F. A.; FONSECA, M. R.; TOURINHO, F. S. A comparative study of severe scorpion envenomation in children caused by Tityus bahiensis and Tityus serrulatus. Rev. Inst. Med. Trop. São Paulo, v. 37, p. 331-336, 1995.

CARNEIRO, A. S.; RIBEIRO, O. G.; DE FRANCO, M.; CABRERA, W. H. K.; VORRARO, F.; SIQUEIRA, M.; IBAÑEZ, O.; STAROBINAS, N. Local inflammatory reaction induced 
by Bothrops jararaca venom differs in mice selected for acute inflammatory response Toxicon, v. 40, p. 1571-1579, 2002.

CARNEIRO, A. S.; RIBEIRO, O. G.; CABRERA, W. H.; VORRARO, F.; DE FRANCO, M.; IBAÑEZ, O. M.; STAROBINAS, N. Bothrops jararaca venom (BjV) induces differential leukocyte accumulation in mice genetically selected for acute inflammatory reaction: the role of host genetic background on expression of adhesion molecules and release of endogenous mediators. Toxicon, v. 52, p. 619-627, 2008.

CARNEIRO, P. S.; PETERS, L. C.; VORRARO, F.; BORREGO, A.; RIBEIRO, O. G.; STAROBINAS, N.; JENSEN, J. R.; CABRERA, W. H.; IBAÑEZ, O. M.; DE FRANCO, M. Gene expression profiles of bone marrow cells from mice phenotype-selected for maximal or minimal acute inflammations: searching for genes in acute inflammation modifier loci. Immunology, v. 128, p. 562-571, 2009.

CATTERAll, W. A; CESTÉlE, S.; YAROV-YAROVOY, V.; YU, F. H.; KONOKI, K.; SCHEUER, T. Voltage-gated ion channels and gating modifier toxins. Toxicon, v. 49, p. 124$141,2007$.

CHÁVEZ-OLORTEGUI, C.; KALAPOTHAKIS, E.; MOREIRA FERREIRA A. M. B.; FERREIRA, A. P.; DINIZ, C. R. Neutralizing capacity of antibodie selicited by a non-toxic protein purified from the venom of the scorpion Tityus serrulatus. Toxicon, v. 35, p. 213-221, 1997.

CHIPPAUX, J. P.; GOYFFON, M. Epidemiology of scorpionism: a global appraisal. Acta Trop., v. 107, p. 71-79, 2008.

COElHO, F. M.; PESSINI, A. C.; COELHO, A. M.; PINHO, V. S.; SOUZA, D. G.; ARANTES, E. C.; TEIXEIRA, M. M.; TEIXEIRA, A. L. Platelet activating factor receptors drive CXC chemokine production, neutrophil influx and edema formation in the lungs of mice injected with Tityus serrulatus venom. Toxicon, v. 50, p. 420-427, 2007.

COLOGNA, C. T.; MARCUSSI, S.; GIGLIO, J. R.; SOARES, A. M.; ARANTES, E. C. Tityus serrulatus Scorpion Venom and Toxins: An Overview. Protein Pept. Lett., v. 16, p. 920-932, 2009.

CORRÊA, M. M.; SAMPAIO, S. V.; LOPES, R. A.; MANCUSO, L. C.; CUNHA, O. A. B.; FRANCO, J. J.; GIGLIO, J. R. Biochemical and histopathological alterations induced in rats by Tityus serrulatus scorpion venom and its major neurotoxin Tityustoxin-I. Toxicon, v. 35, p. 1053-1067, 1997.

CUPO, P.; JURCA, M.; AZEVEDO-MARQUES, M. M.; OLIVEIRA, J. S.; HERING, S. E. Severe scorpion envenomation in Brazil. Clinical, laboratory and anatomopathological aspects. Rev. Inst. Med. Trop. São Paulo, v. 36, p. 67-76, 1994.

CUPO, P.; AZEVEDO-MARQUES, M. M.; HERING, S. E. Escorpionismo. In: CARDOSO, J. L. C.; FRANÇA, F. O. S.; WEN, F. H.; MÁLAQUE, C. M. S.; HADDAD JR, V. Animais peçonhentos do Brasil: biologia, clínica e terapêutica dos acidentes. 2. ed. São Paulo: Sarvier, 2009. p. 198-208. 
CRUZ, A. H.; GARCIA-JIMENEZ, S.; MENDONÇA, R. Z.; PETRICEVICH, V. L. Pro and anti-inflammatory cytokines release in mice injected with Crotalus durissus terrificus venom. Mediators Inflamm., v. 2008, p. 1-10, 2008.

DALLEGRI, F.; OTTONELLO, L. Tissue injury in neutrophilic inflammation. Inflamm. Res., v.46, p.382-91, 1997.

DE FRANCO, M.; COLOMBO, F.; GALVAN, A.; CECCO, L. D.; SPADA, E.; MILANI, S.; IBANEZ, O. M.; DRAGANI, T. A. Transcriptome of normal lung distinguishes mouse lines with different susceptibility to inflammation and to lung tumorigenesis. Cancer Lett., v. 294, p. 187-194, 2010.

DE MATOS, I. M. O.; ROCHA, A.; LEITE, R.; FREIRA-MAIA, L. Lung oedema induced by $T$. serrulatus scorpion venom in the rat. Comp. Biochem. Phyosiol. C. Pharmacol. Toxicol. Endocrinol., v. 118c, p. 143-148, 1997.

DE-MATOS, I. M.; TALVANI, A.; ROCHA, O. O. A.; FREIRE-MAIA, L.; MATOS, M. M. Evidence for a role of mast cells in the lung edema induced by Tityus serrulatus venom in rats. Toxicon, v. 39, p. 863-867, 2001.

DE ROODT, A. R.; LAGO, N. R.; SALOMÓN, O. D.; LASKOWICZ, R. D.; NEDER DE ROMÁN, L. E.; LÓPEZ, R. A.; MONTERO, T. E.; VEGA VDEL, V. A new venomous scorpion responsible for severe envenomation in Argentina: Tityus confluens. Toxicon, v. 53, p. 1-8, 2009.

DI PACE, R. F.; MASSA, S.; RIBEIRO, O. G.; CABRERA W. H. K.; DE FRANCO, M.; STAROBINAS, N.; SEMAN M.; IBAÑEZ O. C. M. Inverse genetic predisposition to colon versus lung carcinogenesis in mouse lines selected based on acute inflammatory responsiveness. Carcinogenesis, v. 27, p. 1517-1525, 2006.

D'SUZE, G.; COMELlAS, A.; PESCE, L.; SEVCIK, C.; SANCHEZ-DE-LEÓN, R. Tityus discrepans venom produces a respiratory distress syndrome in rabbits through an indirect mechanism. Toxicon, v. 37, p. 173-180, 1999.

D’SUZE, G.; MONCADA, S.; GONZÁLEZ, C.; AGUILAR, V.; ALAGÓN, A. Relationship between plasmatic levels of various cytokines, tumor necrosis factor, enzymes and glucose and venom concentration following Tityus scorpion sting. Toxicon, v. 41, p. 367-375, 2003.

D'SUZE, G.; SALAZAR, V.; DÍAZ, P.; SEVCIK, C.; AZPURUA, H.; BRACHO, N. Histopathological changes and inflammatory response induced by Tityus discrepans scorpion venom in rams. Toxicon, v. 44, p. 851-60, 2004.

DUARTE, C. G.; ALVARENGA, L. M.; DIAS-LOPES, C.; MACHADO-DE-AVILA, R. A.; NGUYEN, C.; MOLINA, F.; GRANIER, C.; CHÁVEZ-OLÓRTEGUI, C. In vivo protection against Tityus serrulatus scorpion venom by antibodies raised against a discontinuous synthetic epitope. Vaccine, v. 28, p. 1168-76, 2010.

ECCLES, C. U.; ROGOWSKI, R. S.; GU, X.; ALGER, B. E.; BLAUSTEIN, M. P. Tityustoxin-K $\alpha$, from scorpion venom, blocks voltage-gated, non-inactivating potassium current in cultured central neurons. Neuropharmacology, v. 33, p. 1523-1528, 1994. 
FERNANDES, V. M.; ROMANO-SILVA, M. A.; GOMES, D. A.; PRADO, M. A.; SANTOS, T. M.; GOMEZ, M. V. Dopamine release evoked by beta scorpion toxin, Tityus gamma, in prefrontal cortical slices is mediated by intracellular calcium stores. Cell. Mol. Neurobiol., v. 24, p. 757-767, 2004.

FIALHO, E. M.; MACIEL, M. C.; SILVA, A. C.; REIS, A. S.; ASSUNÇÃO, A. K.; FORTES, T. S., SILVA, L. A.; GUERRA, R. N.; KWASNIEWSKI F. H.; NASCIMENO, F. R. Immune cells recruitment and activation by Tityus serrulatus scorpion venom. Toxicon, $v$. 58, p. 480-485, 2011.

FINNEY, D. J. Probit analysis. Cambridge, England: Cambridge University Press, 1971, p. 31.

FLETCHER JR, P. L.; FLETCHER, M. D.; WENINGER, K.; ANDERSON, T. E.; MARTIN, B.M. Vamp Cleavage by a new Metalloprotease from the brazilian scorpion Tityus serrulatus. J. Biol. Chem., v. 285, p. 7405-7416, 2009.

FREIRE-MAIA, L.; PINTO, I. G.; FRANCO, I. Mechanism of the cardiovascular effects produced by purified scorpion toxin in the rat. J. Pharmacol. Exp. Ther., v. 188, p. 207-213, 1974.

FREIRE-MAIA, L.; CAMPOS, J.A. Pathophysiology and treatment of scorpion poisoning. In: OWNBY, G.V.; ODELL, C.L. (Eds.), Natural toxins: characterization, pharmacology and therapeutics. Oxford, Pergamon Press: p. 139-159, 1989.

FREIRE-MAIA, L.; CAMPOS, J. A.; AMARAL, C. F. S. Approaches to the treatment of scorpion envenoming. Toxicon, v. 32, p. 1009-1014, 1994.

FUKUHARA, Y. D.; REIS, M. L.; DELLALIBERA-JOVILIANO, R.; CUNHA, F. Q.; DONADI, E.A. Increased plasma levels of IL-1beta, IL-6, IL-8, IL-10 and TNF-alpha in patients moderately or severely envenomed by Tityus serrulatus scorpion sting. Toxicon, v. 41, p. 49-55, 2003.

FUKUHARA, Y.D.; DELLALIBERA-JOVILIANO, R.; CUNHA, F.Q.; REIS, M.L.; DONADI, E.A. The kinin system in the envenomation caused by the Tityus serrulatus scorpion sting. Toxicol. Appl. Pharmacol., v. 196, p. 390-395. 2004

FUNDAÇÃO NACIONAL DE SAÚDE, Ministério da Saúde. Manual de diagnóstico e tratamento de acidentes por animais peçonhentos. 2. ed. Brasília: Ministério da Saúde, 2001. p. 37-44.

GAZARIAN, K. G.; GAZARIAN, T.; HERNÁNDEZ, R.; POSSANI, L. D. Immunology of scorpion toxins and perspectives for generation of anti-venom vaccines. Vaccine, v. 23, p. 3357-3368, 2005.

GOMEZ, M. V.; DINIZ, C. R. Separation of toxic components from the Brazilian scorpion Tityus serrulatus venom. Mem. Inst. Butantan, v. 33, p. 899, 1966.

GONÇALVES, A. A.; TOYAMA, M. H.; CARNEIRO, E. M.; MARANGONI, S.; ARANTES, E. C.; GIGLIO, J. R.; BOSCHERO, A. C. Participation of $\mathrm{Na}^{+}$channels in the 
potentiation by Tityus serrulatus $\alpha$-toxin $\mathrm{TsTx}-\mathrm{V}$ of glucose-induced electrical activity and insulin secretion in rodent islet $\beta$-cells. Toxicon, v. 41, p. 1039-1045, 2003.

GUERON, M.; ILIA, R. Non-cardiogenic pulmonary edema after scorpion envenomation: A true entity? Toxicon, v. 34, p. 393-395, 1996.

HOLADAY JR., S. K.; MARTIN, B. M.; FLETCHER JR., P. L.; KRISHNA, N. R. NMR solution structure of butantoxin. Arch. Biochem. Biophys., v. 379, p. 18-27, 2000.

IBAÑEZ, O. M.; STIFFEL, C.; RIBEIRO, O. G.; CABRERA, W. K.; MASSA, S.; DE FRANCO, M.; SANT'ANNA, O. A.; DECREUSEFOND, C.; MOUTON, D.; SIQUEIRA, M.; BIOZZI, G. Genetics of nonspecific immunity: I. Bidirectional selective breeding of lines of mice endowed with maximal or minimal inflammatory responsiveness. Eur. J. Immunol., v. 22, p. 2555-2563, 1992.

JONAS, P.; VOGEL, W.; ARANTES, E. C.; GIGLIO, JR. Toxin $\gamma$ of the scorpion Tityus serrulatus modifies both activation and inactivation of sodium permeability of nerve membrane. Pflügers Arch., v. 407, p. 92-99, 1986.

JOVER, E.; COURAUD, F.; ROCHAT, H. Two types of scorpion neurotoxins characterized by their binding to two separate receptor sites on rat brain synaptosomes. Biochem. Biophys. Res. Commun., v. 95, p. 1607-1614, 1980.

KAPLANSKI, G.; MARIN, V.; MONTERO-JULIAN, F.; MANTOVANI, A.; FARNARIER, C. IL-6: a regulator of the transition from neutrophil to monocyte recruitment during inflammation. Trends Immunol., v. 24, p. 25-29, 2003.

KHATTABI, A.; SOULAYMANI-BENCHEIKH, R.; ACHOUR, S.; SALMI, L. R. Classification of clinical consequences of scorpion stings: consensus development. Trans. R. Soc. Trop. Med. Hyg., v. 105, p. 364-369, 2011.

KRIFI, M. N.; MARRAKCHI, N.; EL AYEB, M.; DELLAGI, K. Effect of some variables on the in vivo determination of scorpion and viper venom toxicities. Biologicals, v. 26, p. 277288, 1998.

LIMA, M. R.; SANTOS, M. C.; TAMBOURGI, D. V.; MARQUES, T.; SILVA, W. D.; KIPNIS, T. Susceptibility of different strains of mice to South American rattlesnake (Crotalus durissus terrificus) venom: correlation between lethal effect and creatine kinase release. Toxicon, v. 29, p. 783-786, 1991.

LOURENÇO, W. R.; CLOUDSLEY-THOMPSOM, J. L. Effects of human activities on the environment and the distribuition of dangerous species of scorpions. In: BON, C.; GOYFFON, M. Editors. Envenomings and their treatments. Lyon: Edit. Fondation M. Merieux, 1996, p. 49-60.

LOURENÇO, W. R.; VON EICKSTEDT, V. R. D. Escorpiões de importancia Médica. In: CARDOSO, J. L. C.; FRANÇA, F. O. S.; WEN, F. H.; MÁLAQUE, C. M. S.; HADDAD, V. JR. Animais peçonhentos do Brasil: biologia, clínica e terapêutica dos acidentes. 2. Ed. São Paulo: Sarvier, 2009. p. 182-197. 
LUSTER, A. D. Chemokines-Chemotactic Cytokines that mediate inflammation. N. Engl. J. Med., v. 338, p. 436-445, 1998.

MAGALHÃES, M. M.; PEREIRA, M. E.; AMARAL, C. F.; REZENDE, N. A.; CAMPOLINA, D.; BUCARETCHI, F.; GAZZINELLI, R. T.; CUNHA-MELO, JR. Serum levels of cytokines in patients envenomed by Tityus serrulatus scorpion sting. Toxicon, v. 37, p. 1155-1164, 1999.

MARIA, D. A.; MANETI, G.; GALBIATI, F.; RIBEIRO, O. G.; CABRERA, W. H. K.; BARRERA, R. G.; PETTINICCHIO, A.; DE FRANCO, M.; STAROBINAS, N.; SIQUEIRA, M.; DRAGANI, T. A.; IBAÑEZ, O. M. Pulmonary adenoma susceptibility 1 (Pas1) locus affects inflammatory response. Oncogene, v. 22, p. 426-432, 2003.

MASSENSINI, A. R.; MORAES-SANTOS, T.; GÓMEZ, M. V.; ROMANO-SILVA, M. A. Alpha and beta-scorpion toxins evoke glutamate release from rat cortical synaptosomes with different effects on $\left[\mathrm{Na}^{+}\right] \mathrm{i}$ and $\left[\mathrm{Ca}_{2}{ }^{+}\right]$i. Neuropharmacology, v. 37, p. 289-297, 1998.

MATOS, I. M.; TEIXEIRA, M. M.; LEITE, R.; FREIRE-MAIA, L. Pharmacological evidence that neuropeptides mediate part of the actions of scorpion venom on the guinea pig ileum. Eur. J. Pharmacol., v. 368, p. 231-236, 1999a.

MATOS, I. M.; SOUZA, D. G.; SEABRA, D. G.; FREIRE-MAIA, L.; TEIXEIRA, M. M. Effects of tachykinin NK1 or PAF receptor blockade on the lung injury induced by scorpion venom in rats. Eur. J. Pharmacol., v. 376, p. 293-300, 1999 b.

MEBS, D. Scorpion and snakes, such as cobras, mambas and vipers made the African continent famous for venomous animals. Bull. Soc. Pathol. Exot., v. 95, p. 131, 2002.

MIRANDA, F.; ROCHAT, H.; LISSITZKY, S. Sur les neurotoxines de deux espèces de scorpions nordafricains.II . Proprietés des neurotoxines (scorpamines) d' Androctonus xustralis (L.) et de Buthus ocritanus (Am.). Toxicon, v. 2, p. 113-121, 1964.

MOSER, B.; WOLF, M.; WALZ, A.; PIUS, L. Chemokines: multiple levels of leukocyte migration control. Trends Immunol., v. 25, p. 75-84, 2004.

MOUHAT, S.; JOUIROU, B.; MOSBAH, A.; DE WAARD, M.; SABATIER, J. M. Diversity of folds in animal toxins acting on ion channels. Biochem. J., v. 378, p. 717-726, 2004.

PADILLA, A.; GOVEZENSKY, T.; POSSANI, L. D.; LARRALDE, C. Experimental envenoming of mice with venom from the scorpion Centruroides limpidus limpidus: differences in mortality and symptoms with and without antibody therapy relating to differences in age, sex and strain of mouse. Toxicon, v. 41, p. 959-65, 2003.

PENG, X.; HASSOUN, P. M.; SAMMANI, S.; MCVERRY, B. J.; MELISSA, J. Protective Effects of Sphingosine 1-Phosphate in Murine Endotoxin-induced Inflammatory Lung Injury. Am. J. Respir. Crit. Care Med., v. 169, p. 1245-1251, 2004.

PERES, A. C. P.; NONAKA, P. N.; CARVALHO, P. T. C.; TOYAMA, M. H.; SILVA, C. A. M.; VIEIRA, R. P.; DOLHNIKOFF, M.; ZAMUNER, S. R.; OLIVEIRA, L.V.F. Effects of 
Tityus serrulatus scorpion venom on lung mechanics and inflammation in mice. Toxicon, v. 53, p. 779-785, 2009.

PESSINI, A. C.; TAKAO, T. T.; CAVALHEIRO, E. C.; VICHNEWSKI, W.; SAMPAIO, S. V.; GIGLIO, JR.; ARANTES, E. C. A hyaluronidase from Tityus serrulatus scorpion venom: isolation, characterization and inhibition by flavonoids. Toxicon, v. 39, p. 1495-1504, 2001.

PESSINI, A. C.; SOUZA, A. M.; FACCIOLO, L. H.; GREGÓRIO, Z. M. O.; ARANTES, E. C. Time course of acute-phase response induced by T. serrulatus venom and TsTX-I in mice. Int. Immunopharmacol., v. 3, p. 765-774, 2003.

PETRICEVICH, V. L.; PENÃ, C. F. The dynamics of cytokine and nitric oxide secretion in mice injected with Tityus serrulatus scorpion venom. Mediators Inflamm., v. 11, p. 173180, 2002.

PETRICEVICH, V. L. Cytokine and nitric oxide production following severe envenomation. Cur.r Drug Targets Inflamm. Allergy, v. 3, p. 325-32, 2005.

PETRICEVICH, V. L. Balance between pro- and antiinflammatory cytokines in mice treated with Centruroides noxius scorpion venom. Mediators Inflamm., v. 2006, p. 1-11, 2006.

PETRICEVICH, V. L.; CRUZ, A. H.; CORONAS, F. I.; POSSANI, L. D. Toxin gamma from Tityus serrulatus scorpion venom plays an essential role in immunomodulation of macrophages. Toxicon, v. 50, p. 666-675, 2007.

PETRICEVICH, V. L.; REYNAUD, E.; CRUZ, A. H.; POSSANI, L. D. Macrophage activation, phagocytosis and intracellular calcium oscillations induced by scorpion toxins from Tityus serrulatus. Clin. Exp. Immunol., v. 154, p. 415-423, 2008.

PETRICEVICH, V.L. Scorpion venom and the inflammatory response. Mediators Inflamm., v. 2010, p. 1-16, 2010.

PICCINI, A. S.; CARTA, S.; TASSI, S.; LASIGLIE, D.; FOSSATI, G.; RUBARTELLI, A. ATP is released by monocytes stimulated with pathogen-sensing receptor ligands and induces IL-1 $\beta$ and IL-18 secretion in an autocrine way. Proc. Natl. Acad. Sci. USA, v. 105, p. 806772, 2008.

POSSANI, L. D.; ALAGÓN, A. C.; FLETCHER, P. L. JR.; ERIKSON, B. W. Purification and properties of mammalian toxins from the Brazilian scorpion Tityus serrulatus Lutz and Mello. Arch. Biochem. Biophys., v. 180, p. 394-403, 1977.

POSSANI, L. D.; MARTIN, B. M.; MOCHCA-MORALES, J.; SVENDESEN, J. Purification and chemical characterization of the major toxins from the venom of the Brazilian scorpion Tityus serrulatus (Lutz and Mello). Carlsberg Res. Commun., v. 46, p. 195-205, 1981.

POSSANI, L. D.; BECERRIL, B.; DELEPIERRE, M.; TYTGAT, J. Scorpion toxins specific for $\mathrm{Na}^{+}$-channels. Eur. J. Biochem., v. 264, p. 287-300, 1999a. 
POSSANI, L. D.; MERINO, E.; CORONA, M.; BOLIVAR, F.; BECERRIL, B. Peptides and genes coding for scorpion toxins that affect ion-channels. Biochimie, v. 82, p. 861-868, 2000 .

PROUST, B.; NAHORI, M. A.; RUFFIE, C.; LEFORT, J.; VARGAFTIG, B. B. Persistence of bronchopulmonary hyper-reactivity and eosinophilic lung inflammation after anti-IL-5 or IL-3 treatment in allergic BALB/c and IL-4Ralpha knockout mice. Clin. Exp. Allergy., v. 11, p. 119-131, 2003.

PUCCA, M. B.; ZOCCAL, K. F.; RONCOLATO, E. C.; BERTOLINI, T. B.; CAMPOS, L. B.; COLOGNA, C. T.; FACCIOLI, L. H.; ARANTES, E. C.; BARBOSA, E. Serrumab: A human monoclonal antibody that counters the biochemical and immunological effects of Tityus serrulatus venom. J. Immunotoxicol., v. 9, p. 173-183, 2012.

RAMOS, A. T.; GONÇALVES, L. R.; RIBEIRO, O. G.; ROCHA CAMPOS, A. C.; SANT'ANNA, O. A. Effects of Lonomia obliqua (lepidoptera, saturniidae) toxin on clotting, inflammatory and antibody responsiveness in genetically selected lines of mice. Toxicon, $\mathrm{v}$. 43, p. 761-768, 2004.

RATES, B.; FERRAZ, K. K. F.; BORGES, M. H.; RICHARDSON, M.; DE LIMA, M. E.; PIMENTA, A. M. C. Tityus serrulatus venom peptidomics: Assessing venom peptide diversity. Toxicon, v. 52, p. 611-618, 2008.

REZENDE, N. A.; DIAS, M. B.; CAMPOLINA, D.; CHAVEZ-OLORTEGUI, C.; RIBEIRO DINIZ, C.; AMARAL, F. S. Efficacy of antivenom therapy for neutralizing circulating venom antigens in patients stung by Tityus serrulatus scorpions. Am. J. Trop. Med. Hyg., v. 52, p. 277-280, 1995.

RIBEIRO, O. G.; MARIA, D. A.; ADRIOUCH, S.; PECHBERTY, S.; CABRERA, W.H.; MORISSET. J.; IBAÑEZ, O.M.; SEMAN, M. Convergent alteration of granulopoiesis, chemotactic activity, and neutrophil apoptosis during mouse selection for high acute inflammatory response. J. Leukoc. Biol., v. 74, p. 497-506, 2003.

RIBEIRO, O. G.; WAFA, H. C.; MARIA, D. A.; DE FRANCO, M.; MASSA, S.; DI PACE, F.; SOUZA, V. R. C.; STAROBINAS, N.; SEMEN, M.; IBAÑEZ, O. M. Genetic selection high acute inflammatory response confers resistance to lung carcinogenesis in the mouse. Exp. Lung Res., v. 31, p. 105-116, 2005

RIBEIRO, E. L.; PINTO, M. C. L.; LABARRÈRE, C. R.; PAES, P. R. O.; PAES-LEME, F. O.; CHÁVEZ-OLÓTERGUI, C. D.; MELO, M. M. Biochemical profile of dogs experimentally envenomed with Tityus serrulatus scorpion venom. Toxicon, v. 55, p.1125$1131,2010$.

ROCHAT, H.; KOPEYAN, C.; GARCIA, L. G.; MARTINEZ, G.; ROSSO, J. P.; PAKARIS, A.; MARTIN, M. F.; GARCIA, A.; MARTIN-MOUTOT, N.; GREOOIRE, J.; MIRANDA, F. Recent results on the structure of Tityus serrulatus Toxins 277 scorpion and snake toxins. In : OSAKA, A., HAYASHI, K. ; SAWAI, Y. Eds. Animal plant and microbial toxins., New York: Plenum Press, 1976, v. 2, p.79. 
SAADI, S.; WRENSHALL, L. E.; PLATT, J. L. Regional manifestations and control of the immune system. FASEB J., v. 16, p. 849-856, 2002.

SEVERINO, D. N.; PEREIRA, R. L.; KNYSAK, I.; CÂNDIDO, D. M.; KWASNIEWSKI, F. $\mathrm{H}$. Edematogenic activity of scorpion venoms from the Buthidae family and the role of platelet-activating factor and nitric oxide in paw edema induced by Tityus venoms. Inflammation, v. 32, p. 57-64, 2009.

SIROIS, M. G.; JANCAR, S.; BRAQUET, P.; PLANTE, G. E.; SIROIS, P. PAF increases vascular permeability in selected tissues: effect of BN-52021 and L-655,240. Prostaglandins, v. 36, p. 631-644, 1988.

SISSOM, W. D. Systematics, Biogeography and Paleontology. In: POLIS, G.A. editor. The biology of scorpions. Stanford Univ. Press, 1990, p. 64-160.

SOFER, S.; GUERON, M.; WHITE, R. M.; LIFSHITZ, M.; APTE, R. N. Interleukin-6 release following scorpion sting in children. Toxicon, v. 34, p. 389-392, 1996.

SOUZA, C. A. R.; CANDIDO, D. M.; LUCAS, S. M.; BRESCOVIT, A. D. On the Tityus stigmurus complex (Scorpiones, Buthidae). Zootaxa, v. 1987 p. 1-38, 2009.

STIFFEL, C.; IBANEZ, O. M.; RIBEIRO, O. G.; DECREUSEFOND, C.; MOUTON, D.; SIQUEIRA, M.; BIOZZI, G. Genetics of acute inflammation: inflammatory reactions in inbred lines of mice and in their interline crosses. Exp. Clin. Immunogenet. v. 7, p. 221-233, 1990.

SUPPA, A. P. Estudo da expressão dos genes regulatórios da hipóxia durante a inflamação pulmonar produzida pela isquemia e reperfusão intestinal em camundongos AIRmax e AIRmin. 2009. 90 f. Dissertação (Mestrado em Biotecnologia) - Instituto de Ciências Biomédicas, Universidade de São Paulo, São Paulo, 2009.

TAMBOURGI, D. V.; PETRICEVICH, V. L.; MAGNOLI, F. C.; ASSAF, S. L. M. R.; JANCAR, S.; DIAS DA SILVA, W. Endotoxemic-like shock induced by Loxosceles spider venoms: pathological changes and putative cytokine mediators. Toxicon, v. 36, p. 391-403, 1998.

TAN, N. H.; PONNUDURAI, G. Comparative study of the enzymatic, hemorrhagic, procoagulant and anticoagulant activities of some animal venoms. Comp. Biochem. Physiol. C., v. 103, p. 299-302, 1992.

TOLEDO, D. V.; NEVES, A. G. A. Purification and partial characterization of a second toxin from the scorpion Tityus serrulatus. Comp. Biochem. Physiol. B., v. 249, p. 249-253, 1976.

TYTGAT, J.; CHANDY, K. G.; GARCIA, M. L. A unified nomenclature for short-chain peptides isolated from scorpion venoms: $\alpha$-KTx molecular subfamilies. Trends Pharmacol. Sci., v. 20, p. 444-447, 1999.

VASCONCELOS, F.; LANCHOTE, V. L.; BENDHACK, L. M.; GIGLIO, JR.; SAMPAIO, S. V.; ARANTES, E. C. Effects of voltage-gated $\mathrm{Na}^{+}$channel toxins from Tityus serrulatus 
venom on rat arterial blood pressure and plasma catecholamines. Comp. Biochem. Physiol. C. Toxicol. Pharmacol., v. 141, p. 85-92, 2005.

VERANO-BRAGA, T.; ROCHA-RESENDE, C.; SILVA, D. M.; IANZER, D.; MARTINEAUCLAIRE, M. F.; BOUGIS, P. E.; DE LIMA, M. E.; SANTOS, R. A. S.; PIMENTA, A. M. C. Tityus serrulatus Hypotensins: A new family of peptides from scorpion venom. Biochem. Biophys. Res. Commun., v. 371, p. 515-520, 2008.

VICTONI, T. Avaliação dos mecanismos indutores da inflamação pulmonar decorrentes da isquemia e reperfusão intestinal em camundongos geneticamente selecionados. 2008. 70 f. Dissertação (Mestrado em Farmacologia) - Instituto de Ciências Biomédicas, Universidade de São Paulo, São Paulo, 2008.

VIGAR, N. D.; CABRERA, W. H.; ARAUJO, L. M.; RIBEIRO, O. G.; OGATA, T. R,; SIQUEIRA, M.; IBAÑEZ, O. M.; DE FRANCO, M. Pristane-induced arthritis in mice selected for maximal or minimal acute inflammatory reaction. Eur. J. Immunol., v. 30, p. 431-437, 2000.

VORRARO, F.; GALVAN, A.; CABRERA, W. H. K.; CARNEIRO, P. S.; RIBEIRO, O. G.; DE FRANCO, M.; STAROBINAS, N.; JENSEN, J. R.; SEMAN, M.; DRAGANI, T. A.; IBAÑEZ, O. C. M. Gene control of IL-1 $\beta$ production and inflammatory response by the mouse Irm1 locus. J. Immunol., v. 185, p. 1616-1621, 2010

VORRARO, F.; GALVAN, A.; CABRERA, W. H. K.; RIBEIRO, O. G.; STAROBINAS, N.; JENSEN, J. R.; CARNEIRO, P. S.; DE FRANCO, M. GAO, X.; IBAÑEZ, O. M.; DRAGANI, T. A. Association study by genetic clustering detects multiple inflammatory response loci in non-inbred mice. Genes Immun., v. 12, p. 390-394, 2011.

LAZDUNSKI, M. Specific binding of toxin II from Centruroides suffusus suffusus to the sodium channel in electroplaque membranes. Biochemistry. v.21, n.22, p.5628-5634, 1982.

ZOCCAL, K. F.; BITENCOURT, C. S.; SECATTO, A.; SORGI, C. A.; BORDON, K. C. F.; SAMPAIO, S. V.; ARANTES, E. C.; FACCIOLI, L. H. Tityus serrulatus venom and toxins Ts1, Ts2 and Ts6 induce macrophage activation and production of immune mediators. Toxicon, v. 57, p. 1101-1108, 2011.

ZULIANI, J. P.; FREITAS, T. A.; CONCEIÇÃO I. M.; KWASNIEWSKI, F. H. Tityus serrulatus venom increases vascular permeability in selected airway tissues in a mast cell-independent way. Exp. Toxicol. Pathol., 2011. In press. 